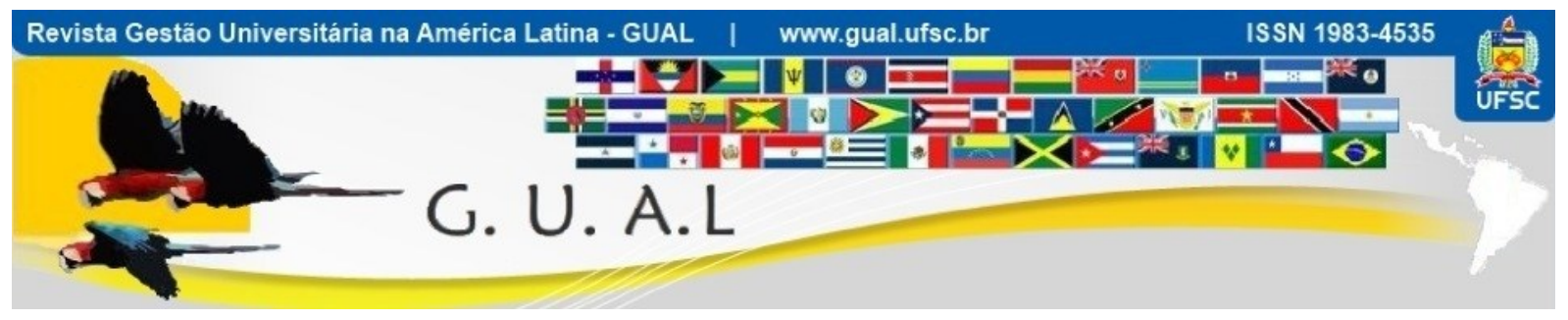

DOI: http://dx.doi.org/10.5007/1983-4535.2012v5n2p217

\title{
MÍDIAS SOCIAIS COMO ESTRATÉGIA DE COMUNICAÇÃO EM UMA INSTITUIÇÃO DE ENSINO: PERSPECTIVAS E DESAFIOS
}

\section{SOCIAL MEDIA AS COMMUNICATION STRATEGY FOR AN EDUCATIONAL INSTITUTION: PERSPECTIVES AND CHALLENGES}

Daniel Augustin Pereira, Mestre Instituto Federal de Educação, Ciência e Tecnologia de Santa Catarina - IF-SC daniel.esag@yahoo.com.br

Martha Kaschny Borges, Doutora Universidade do Estado de Santa Catarina - UDESC marthakaschny@hotmail.com

Recebido em 29/outubro/2011

Aprovado em 14/março/2012

Sistema de Avaliação: Double Blind Review

Esta obra está sob uma Licença Creative Commons Atribuição-Uso. 


\title{
RESUMO
}

A educação profissional e tecnológica, bem como as instituições que oferecem essa modalidade de ensino, têm conquistado espaço na agenda de discussões da sociedade brasileira. Ao mesmo tempo, as pessoas e as instituições têm prestado cada vez mais atenção às novas tecnologias ligadas à comunicação, principalmente às mídias sociais. Nesse contexto, o Instituto Federal de Santa Catarina (IF-SC) passou a adotar, desde 2008, as mídias sociais como estratégia comunicacional com seus públicos-alvo: alunos, servidores e a comunidade em geral. Esta pesquisa, do tipo estudo de caso, tem o objetivo de analisar as percepções dos profissionais de comunicação da referida instituição com relação ao uso institucional dessas mídias. Os resultados - obtidos a partir de entrevistas, documentos e registros em arquivos - foram analisados por meio do método de análise de conteúdo. As categorias de análise que emergiram são relativas à coexistência das mídias sociais em meio aos demais canais de comunicação, aos benefícios e às principais dificuldades que impedem uma utilização mais efetiva dessas mídias. Entre os principais benefícios estão a aproximação entre instituição e seus públicos-alvo, o estabelecimento de um canal de comunicação de mãodupla e a facilitação do acesso às informações sobre o IF-SC. No entanto, dificuldades de organização interna limitam o uso das mídias sociais como ferramentas eficientes de comunicação organizacional.

Palavras-chave: Comunicação organizacional. Mídias sociais. Educação profissional. Instituições de ensino. Estratégia.

\begin{abstract}
Professional and technological education, along with the institutions that offer this kind of education, have conquered space in the agenda of Brazilian society. At the same time, people and institutions are paying more attention to new technologies related to communication, especially the social media. In this context, Santa Catarina's Federal Institute (IF-SC) started adopting, since 2008, social media as a communication strategy with its target audiences: students, staff and the community itself. This case study research aims to analyze the perceptions of IF-SC's communication professionals as to the institutional use of social media. The results - obtained from interviews, documents and file records - were analyzed using the method of content analysis. The categories of analysis that have emerged are related to the coexistence of social media tools among other communication channels, the benefits and the difficulties that prevent a more effective use of social media in the institution. Among the identified benefits are the rapprochement between the IF-SC and its target audiences, the establishment of a two-way communication channel and the facilitation of access to information about the institution. However, internal organizational difficulties still limit the use of social media as a more effective tool for organizational communication on IF-SC.
\end{abstract}

Keywords: Organizational communication. Social media. Professional education. Educational institutions. Strategy. 


\section{INTRODUÇÃO}

A área da educação no Brasil tem passado por um período de crescimento e expansão notórios em diversos níveis e modalidades de ensino. Números levantados pelo Instituto Nacional de Estudos e Pesquisas Educacionais Anísio Teixeira referentes ao Censo Escolar da Educação Básica mostram que, entre 2005 e 2010, a quantidade de alunos matriculados na Educação Profissional no Brasil aumentou 52,48\%. Do total registrado em 2010, 14,49\% estavam matriculados em instituições públicas federais (INEP, 2011).

Seguindo também uma tendência de crescimento, o mesmo instituto constatou, desta vez por meio do Censo da Educação Superior, que em período semelhante - entre 2005 e 2009 - o número de matrículas nos cursos de graduação presenciais e a distância aumentou 30,34\%. Do total registrado em 2009, 14,10\% estavam matriculados em instituições públicas federais (INEP, 2011).

Os levantamentos mostram ainda um aumento contínuo no número de instituições de ensino no país. No que se refere à educação superior, a quantidade de instituições cresceu $6,8 \%$ entre 2005 e 2009. Para as instituições de educação profissional, o aumento no mesmo período foi de 9,4\%. Na educação profissional, em especial, a quantidade de instituições federais passou de 146 para 210, ou seja, um aumento de 43,8\% (INEP, 2011).

Nesse contexto, o Ministério da Educação estimula, desde 2007, a ampliação das instituições federais de ensino. Uma das principais medidas tem sido a expansão da Rede Federal de Educação Profissional e Tecnológica, composta por 38 Institutos Federais de Educação, Ciência e Tecnologia, os quais têm ampliado o número de vagas para os cursos técnicos e de graduação, criando novos cursos em áreas consideradas estratégicas regionalmente.

Essa perspectiva de expansão continuada do setor vem acompanhada por uma série de desafios, pontuados por Las Casas e Las Casas (2008), que dizem respeito ao crescimento do mercado e da quantidade de serviços ofertados, à medição da qualidade do serviço prestado em educação, à mudança em diversos aspectos do processo de aprendizado e à evolução das tecnologias da informação e da comunicação, dentre outros.

Em relação à expansão das tecnologias da informação e da comunicação, o desafio é grande. Os públicos com os quais essas instituições lidam - adolescentes e jovens, principalmente - participam das significativas mudanças promovidas por meio dessa expansão. 
De acordo com Kaplan (1993), a comunicação entre as instituições e seus públicos é um elemento estratégico que permeia as ações dessas instituições e favorece o alcance dos objetivos organizacionais. Entretanto, esse aspecto muitas vezes não é tratado como um enfoque estratégico. Muitas vezes, as ações e os esforços realizados não alcançam os objetivos esperados pelos gestores das instituições.

A comunicação entre as instituições de ensino e a sociedade, como as da Rede Federal de Educação Profissional e Tecnológica, configura-se como uma necessidade legal de transparência relativamente às atividades do ensino, pesquisa e extensão dessas instituições (BRASIL, 1996; DELORS, 1998). Afinal, é por meio dos canais de comunicação que a sociedade pode conhecer suas ações e projetos.

A apropriação das tecnologias por um número cada vez maior de pessoas em todas as classes sociais faz com que haja um aumento no acesso a sites e serviços existentes na internet. Entre os mais acessados, destacam-se os sites de redes sociais como Facebook, Orkut e Twitter, dentre outros. Esse fato pode ser verificado na revista Info Online. Segundo essa revista, o site do Facebook foi o mais acessado no final de dezembro de 2009, superando inclusive os serviços de buscadores da internet como Google, Yahoo! e Bing (VALLE, 2009).

Nesse cenário, o Instituto Federal de Educação, Ciência e Tecnologia de Santa Catarina (IF-SC), uma instituição de ensino público, federal, atuante em todas as regiões do estado catarinense e que oferece cursos em diversos níveis e modalidades da educação profissional e tecnológica, utiliza desde 2008 os sites de redes sociais, também conhecidos como "mídias sociais", para ampliar as formas de comunicação com seus públicos-alvo: alunos, servidores (docentes e técnico-administrativos) e comunidade externa.

Assim, o objetivo desta pesquisa é analisar os impactos que o uso das mídias sociais pelo IF-SC promove em seu processo comunicacional junto aos públicos-alvo e contribuir para o aprimoramento das ações de comunicação e de gestão institucionais, como uma ação estratégica da instituição.

As redes sociais são caracterizadas por Steiner (2006) como um conjunto de atores que estão ligados entre si por meio de relações, formando vínculos diretos e indiretos entre seus integrantes (pessoas, instituições, agentes de mercado ou outras formas de organização). Esse conceito, aplicado ao suporte midiático proporcionado pela internet, constitui as mídias sociais (popularmente difundidas com nome de "redes sociais" ou, também, "sites de relacionamento" e "sites sociais"). 
As mídias sociais, conforme Weinberg (2009), conectam milhões de indivíduos segundo suas afinidades, dando a eles e também às organizações que atuam em rede o poder de buscar, compilar, produzir e disseminar informações. Do ponto de vista das instituições, essas informações podem dizer respeito a experiências vivenciadas com produtos ou serviços oferecidos, não sendo possível para uma organização controlar o conteúdo que é repassado de um ator para outro.

Além disso, Kaplan (1993) lembra que uma organização considerada boa comunicadora não é aquela que apenas emite informações. Uma boa comunicação consiste na emissão e na recepção de informações junto ao público-alvo, na adaptação da comunicação à melhor linguagem, canal e forma, no ajuste contínuo da comunicação às necessidades e mudanças ocorridas com o público e na aplicação de princípios estratégicos à comunicação organizacional. Nesse sentido, a utilização das mídias sociais por instituições como canal de comunicação surge como uma opção estratégica, tendo em vista as possibilidades de troca de informação entre os atores on-line, a evolução e a adaptação contínuas do conteúdo propagado, o poder de alcance das mensagens que se utilizam desse canal e a aproximação gerada entre a instituição e o público. As mídias sociais não são uma "coisa" no mesmo sentido que uma ferramenta de mala direta ou um anúncio de $\mathrm{TV}$, mas um processo colaborativo por meio do qual a informação é criada, compartilhada, alterada e reconstruída (SAFKO; BRAKE, 2009).

O IF-SC cria, em 2009, a Diretoria de Comunicação, articulada à Pró-Reitoria de Extensão e Relações Externas. Essa diretoria, por sua vez, criou a Coordenadoria de Jornalismo, responsável pelas ações de comunicação entre a instituição e seus públicos-alvo (internos ou externos). Tal coordenadoria, em 2010, era composta por três jornalistas e ainda tem a função de gerenciar as mídias sociais adotadas.

\section{O CAMINHO PERCORRIDO NA INVESTIGAÇÃO}

A pesquisa, desenvolvida no curso de mestrado profissional em Administração da Universidade do Estado de Santa Catarina, se caracteriza como um estudo de caso, de caráter qualitativo (YIN, 2005; OLIVEIRA NETTO, 2008).

Para sua realização, optou-se pela coleta de informações a partir de documentos e arquivos disponibilizados pela Diretoria de Comunicação e pela realização de entrevistas semiestruturadas junto aos principais agentes responsáveis pelas mídias sociais no IF-SC: o 
coordenador de jornalismo, um dos jornalistas da Coordenadoria de Jornalismo e, ainda, o diretor de comunicação da instituição. Tais atores foram escolhidos de forma intencional, uma vez que são os sujeitos com maior responsabilidade tanto política quanto operacional na implantação e no uso das mídias sociais pela instituição.

A metodologia de coleta de dados teve por base as técnicas propostas por Yin (2005), denominadas "fontes de evidências". São elas:

- documentação - a análise de documentos da instituição visou valorizar as evidências obtidas por meio de outras fontes, destacando a relação entre o IF-SC e o uso das mídias sociais. Dentre os documentos analisados, destacam-se os relatórios de gestão e os documentos de planejamento dos próximos anos;

- registros em arquivo - geralmente assumindo a forma de arquivos e registros digitais, foram analisados em conjunto com as outras fontes de informação. Dentre esses itens encontravam-se documentos ligados ao planejamento da instituição e da Diretoria de Comunicação, e-mails e relatórios sobre atividades da Coordenadoria de Jornalismo;

- entrevistas - uma das mais importantes fontes de informação para o estudo. Foram realizadas três entrevistas semiestruturadas, com base em um roteiro previamente desenvolvido a partir da revisão da literatura e da análise de documentos e arquivos.

Após a realização das entrevistas, os dados foram transcritos e a seguir analisados segundo o método de análise de conteúdo (BARDIN, 2009). De acordo com Bardin (2009, p. 33), a análise de conteúdo caracteriza-se como "um conjunto de técnicas de análise das comunicações”. Esse método utiliza procedimentos sistemáticos e objetivos de descrição do conteúdo das mensagens, ou seja, o interesse não está apenas na descrição dos conteúdos, mas sim no que estes podem significar após serem tratados.

\section{A REALIDADE DA COMUNICAÇÃO NO IF-SC}

O IF-SC é uma autarquia do Governo Federal fundada em 1909 e que, ao longo de sua história, teve diversas nomenclaturas. As mais conhecidas são: Escola Técnica Federal de Santa Catarina (como foi denominada entre 1968 e 2002) e Centro Federal de Educação Tecnológica de Santa Catarina - ou Cefet-SC (entre 2002 e 2008).

A instituição é uma organização pública federal com status de universidade, o que lhe permite oferecer cursos em diversas áreas e modalidades, desde o ensino de curta duração até os níveis técnico, superior e de pós-graduação. Como Instituto Federal, a instituição voltou 
seus esforços para a verticalização e a interiorização da educação no seu território de atuação. (BRASIL, 2008b; IF-SC, 2009).

À época da realização desta pesquisa, a instituição possuía 8.503 alunos matriculados em seus cursos de nível médio, técnico, superior e de pós-graduação. Era composta, ainda, por 1.275 funcionários, que atuavam na Reitoria ou em um dos 20 campi existentes (IF-SC, 2010a).

Como resultado da análise cruzada das três fontes de evidência consideradas (documentos institucionais, arquivos digitais e entrevistas), foi possível identificar as atribuições da Diretoria de Comunicação e da Coordenadoria de Jornalismo. A primeira tem como finalidade definir, propor e fiscalizar as ações institucionais de comunicação interna e externa, promovendo uma profissionalização contínua do setor de comunicação e coordenando o crescimento dessa área. É responsável por realizar capacitações dos servidores que atuam na área de comunicação na Reitoria e nos campi.

Já a Coordenadoria de Jornalismo tem o papel de desenvolver e manter produtos e ferramentas de comunicação para o IF-SC, assegurando o fluxo de informações entre a instituição e seus públicos-alvo. O formato desses produtos e ferramentas varia desde o impresso até o on-line. Os públicos elencados são os alunos, os servidores, a imprensa e a comunidade externa. Além disso, a Coordenadoria de Jornalismo tem como missão promover e melhorar a imagem do IF-SC junto à sociedade em geral.

A análise das entrevistas permitiu a identificação de três categorias relacionadas ao uso das mídias sociais: "mídias sociais como novas possibilidades de comunicação", "potencialidades das mídias sociais" e "dificuldades que se tornam desafios".

\subsection{Mídias sociais como novas possibilidades de comunicação}

A Coordenadoria de Jornalismo possui diversas ferramentas institucionais para efetivar a comunicação entre a instituição e seus públicos-alvo. Estas são gerenciadas de forma centralizada e têm a contribuição de servidores dos campi do IF-SC por meio dos coordenadores de Extensão e Relações Externas, que atuam a partir dos campi e devem apoiar as atividades de comunicação institucional.

A síntese dos canais de comunicação do IF-SC e a relação desses canais com os públicos-alvo são apresentadas no quadro a seguir. Salienta-se que, mesmo que os públicos- 
alvo atribuídos aos canais estejam definidos, esses públicos podem acessar os canais que não são direcionados a eles (exceto a intranet, cujo acesso exige cadastro prévio).

\begin{tabular}{|ll|}
\hline Canal de comunicação & Público-alvo \\
\hline Informativo impresso bimestral (Jornal Contato) & Alunos e comunidade externa \\
\hline Informativo eletrônico semanal (Link Digital) & Servidores \\
\hline Site externo do IF-SC ${ }^{(1)}$ & Alunos e comunidade externa \\
\hline Intranet $^{(2)}$ & Servidores \\
\hline E-mail "Todos" $^{(2)}$ & Servidores \\
\hline Mídias Sociais $^{(3)}$ & Alunos, imprensa e comunidade externa \\
\hline
\end{tabular}

Quadro 1 Canais de comunicação de responsabilidade da Coordenadoria de Jornalismo Nota: (1) Seção de notícias. (2) A Diretoria de Comunicação não é a única área dentro da instituição responsável pela utilização e manutenção deste canal. (3) Alguns campi possuem ferramentas próprias dentro desse canal de comunicação, em paralelo à Coordenadoria de Jornalismo.

Fonte: Elaborado pelos autores.

O Jornal Contato é impresso bimestralmente e é entregue em todos os campi do IF-SC, ficando à disposição de alunos, servidores e comunidade. O Link Digital é enviado semanalmente a todos os servidores que fazem parte da lista interna de e-mails da instituição. $\mathrm{O}$ site externo possui atualização diária em sua seção de notícias. Na intranet, a Coordenadoria de Jornalismo publicou 100 notícias. O e-mail "Todos" permite o envio de mensagens ao e-mail de cada servidor da instituição e é utilizado apenas quando há urgência em informar a respeito de algum acontecimento. Já as mídias sociais, por estarem diretamente ligadas ao objetivo desta pesquisa, serão tratadas em separado.

De acordo com Safko e Brake (2009), a presença de uma instituição nas mídias sociais é uma tendência e uma forma de aproximar as organizações dos seus públicos, com vistas a uma melhora na qualidade das mensagens transmitidas. Essa preocupação parece estar presente no IF-SC, uma vez que a Diretoria de Comunicação utiliza seis mídias sociais com essa finalidade.

\begin{tabular}{|lll|}
\hline Mídia social & Públicos atendidos & Conteúdos predominantes \\
\hline Twitter & Alunos, servidores, imprensa, comunidade & $\begin{array}{l}\text { Notícias, eventos, oportunidades, avisos, } \\
\text { fotos }\end{array}$ \\
\hline Facebook & Alunos, servidores, comunidade & Eventos e coberturas fotográficas \\
\hline Orkut & Alunos, servidores, comunidade & Eventos e oportunidades \\
\hline YouTube & Alunos, servidores, comunidade & $\begin{array}{l}\text { Vídeos institucionais e clipagem de mídia } \\
\text { televisionada }\end{array}$ \\
\hline Formspring & Alunos, comunidade & Dúvidas sobre a instituição \\
\hline Blog & Alunos, servidores, imprensa, comunidade & $\begin{array}{l}\text { Cobertura anual da Semana de Ciência e } \\
\text { Tecnologia }\end{array}$ \\
\hline
\end{tabular}

Quadro 2 Mídias sociais utilizadas pela Coordenadoria de Jornalismo do IF-SC

Fonte: Elaborado pelos autores. 
A mídia social há mais tempo utilizada pelo IF-SC é o Twitter. Por meio do perfil “@ifsc”, a Coordenadoria de Jornalismo realiza postagens diárias, que são visualizadas por cerca de quase três mil usuários. No Facebook, a página do IF-SC é acessada por cerca de 680 pessoas que recebem as atualizações publicadas pela instituição, diversas vezes por semana. No Orkut, a comunidade "IF-SC Eventos e Oportunidades" possui aproximadamente 100 membros, os quais podem conferir os próximos eventos e as oportunidades na instituição. No YouTube, o canal "IF-SC Comunicação" foi criado para receber vídeos institucionais e divulgar reportagens em vídeo de que o IF-SC participa. Porém, esse canal é pouco utilizado pela Coordenadoria de Jornalismo e está no aguardo de novos produtos comunicacionais que possam ser veiculados nele. No Formspring, o IF-SC responde a diversas dúvidas relacionadas aos cursos oferecidos e às ações da instituição que interferem na rotina dos alunos. Por fim, o blog da Semana Nacional de Ciência e Tecnologia do IF-SC é utilizado anualmente para divulgar esse evento. Ele recebe um número cada vez maior de visitas: de 2009 para 2010, registrou-se um aumento de 13,55\% de acessos (IF-SC, 2011).

Alguns outros campi da instituição também estão usando as mídias sociais para interagirem com a comunidade interna e externa. Esse trabalho é realizado pelos coordenadores de Extensão e Relações Externas (ver quadro a seguir). Dentre essas iniciativas, podem ser citadas a criação de novos perfis no Twitter (por exemplo: “@ifscfloripa”), perfis no Facebook (por exemplo: "Campus Canoinhas Ifsc") e canais no Youtube (por exemplo: "www.youtube.com/ifscchapeco").

Esse aumento da participação do IF-SC nas mídias sociais vai ao encontro do que Safko e Brake (2009) apontam como tendência na atualidade, salientando o aspecto espontâneo dessas iniciativas e do fluxo de informação que elas promovem.

\begin{tabular}{|ll|}
\hline Mídia social & Responsáveis \\
\hline Twitter & $\begin{array}{l}\text { Coordenadoria de Jornalismo e campi (Florianópolis, Joinville, Araranguá, } \\
\text { Jaraguá do Sul, Gaspar) }\end{array}$ \\
\hline Facebook & $\begin{array}{l}\text { Coordenadoria de Jornalismo e campi (Joinville, Jaraguá do Sul, Gaspar, } \\
\text { Canoinhas) }\end{array}$ \\
\hline Orkut & $\begin{array}{l}\text { Coordenadoria de Jornalismo } \\
\text { Youtube }\end{array} \begin{array}{l}\text { Coordenadoria de Jornalismo e campi (Joinville, Chapecó, Araranguá, } \\
\text { Jaraguá do Sul) }\end{array}$ \\
\hline Formspring & Coordenadoria de Jornalismo \\
\hline Blog & Coordenadoria de Jornalismo \\
\hline
\end{tabular}

Quadro 3 Mídias sociais e sua descentralização dentro do IF-SC Fonte: Elaborado pelos autores. 
Percebe-se que cada uma das mídias sociais utilizadas possui conteúdos específicos e apresenta um direcionamento determinado dentro das ações de comunicação da instituição. Tal forma de atuação, assim como a presença em mais de uma mídia social, é observada como positiva, desde que haja integração entre elas (SAFKO; BRAKE, 2009). Nesse sentido, a Coordenadoria de Jornalismo afirma usar cada uma das mídias para compartilhar um determinado tipo de informação e, quando possível, favorecer a integração entre os canais controlados pela Reitoria.

A gente faz uma matéria e divulga nos diferentes canais, conforme o público, de forma diferente. Então uma coisa que a gente publica no site, às vezes a gente publica na intranet com mais detalhes porque é pra servidor, publica de uma forma mais chamativa no Twitter pra levar o pessoal pro site. [...] E no Facebook também, a gente coloca informações e fotos. ${ }^{1}$

A utilização das mídias sociais vem apresentando alguns resultados, conforme afirmam os profissionais entrevistados. Esses resultados são discutidos na próxima categoria de análise.

\subsection{Potencialidades das mídias sociais}

Um dos resultados apontados é o aumento da audiência das mensagens antes publicadas exclusivamente em canais tradicionais, como o site externo do IF-SC. Nesse site, que é considerado pelos entrevistados como uma das principais formas de acesso dos alunos e da comunidade externa às informações do Instituto Federal, as notícias referentes ao lançamento de editais, a eventos e ao próprio funcionamento da educação profissional tiveram um crescimento de, em média, 10\% no número de acessos.

Um levantamento realizado pela Coordenadoria de Jornalismo no final de 2010 mostrou que a divulgação via Twitter, por exemplo, chegou a ser responsável por até 13,13\% do número de acessos das notícias. Ao mesmo tempo, porém, houve notícias em que o número de acessos via Twitter representou apenas 0,32\% do total (IF-SC, 2011).

Apesar da significativa variação no número de acessos estimulados por meio do Twitter, o resultado percebido evidencia a capacidade que as mídias sociais possuem para apoiar a divulgação de informações antes disponíveis apenas em canais tradicionais. Essa capacidade é ressaltada tanto pelo jornalista quanto pelo coordenador de Jornalismo entrevistados:

\footnotetext{
${ }^{1}$ Transcrição de entrevista realizada com jornalista. 
Mídias sociais, como eu falei, hoje não são o principal meio de comunicação, mas são um meio complementar importante... importantíssimo, na verdade, para a instituição ${ }^{2}$.

Dependendo da informação, eu acho que ela funciona bem, mas mesmo assim eu acho que, sozinha, a mídia social não se basta. Até porque, por ser mídia social e ter aquela questão da instantaneidade, sempre tem uma coisa nova que vai aparecendo, e então a informação anterior vai caindo. ${ }^{3}$

O tipo de conteúdo assinalado pelos entrevistados que mais tem repercutido e obtido um resultado positivo está vinculado aos aspectos de instantaneidade e de espontaneidade. Entre as informações que mais caracterizam esse tipo de conteúdo estão aquelas com que o público-alvo se identifica: as que o fazem sentir-se prestigiado, instigado a realizar alguma ação ou que o fazem perceber como válido o repasse dessa informação aos demais agentes de suas redes sociais. Exemplos que evidenciam esse aspecto foram apresentados pelo coordenador de Jornalismo e pelo jornalista entrevistados, conforme as citações a seguir.

Por exemplo, faz um tempo que a gente teve até uma enquete de torcida de futebol. Às vezes quando tem entrevista, assim, em programas de TV para jovens, a gente convida o pessoal pelo Twitter dizendo "ó, quem quer participar?", algo que os alunos e a própria comunidade possam interagir com a gente. ${ }^{4}$

Eu lembro que a gente colocou, bem pra atiçar a curiosidade, que a reitora foi participar de uma reunião com o presidente Lula, e a gente não falava o que era. A gente falava "quer saber sobre o que foi, clique aqui". Teve um monte de acessos! Não sei se as pessoas realmente leram a matéria, mas muitos utilizaram o Twitter pra chegar à nossa página. ${ }^{5}$

Os exemplos demonstram que a Diretoria de Comunicação tem procurado dialogar com seus públicos-alvo por meio das mídias sociais, conforme aconselham Hay (2009) e Weinberg (2009). Para ele, estar presente nas mídias sociais não é suficiente; é preciso participar efetivamente desse universo, estabelecendo conversas e interagindo com os demais agentes da rede social. Esse tipo de ação contribui fortemente para o sucesso da instituição em meio ao público e em detrimento das organizações concorrentes que não se preocupam com a interação (WEINBERG, 2009).

Outros fatores positivos também foram percebidos pela área de comunicação, como a velocidade da informação e a forma direta de relacionamento junto aos alunos e à comunidade

\footnotetext{
${ }^{2}$ Transcrição de entrevista realizada com coordenador de Jornalismo.

${ }^{3}$ Transcrição de entrevista realizada com jornalista.

${ }^{4}$ Transcrição de entrevista realizada com coordenador de Jornalismo.

${ }^{5}$ Transcrição de entrevista realizada com jornalista.
} 
externa, principalmente por meio do Twitter e do Facebook. De acordo com Safko e Brake (2009), esses fatores são possibilitados quando a organização e seu público utilizam canais adequados e semelhantes para estabelecer uma comunicação dinâmica. O exemplo abaixo evidencia essa convergência e a eficiência das mídias sociais na comunicação do IF-SC.

A gente teve um caso legal que foi um dia, neste semestre agora, que as aulas do campus Florianópolis, o nosso maior campus, foram canceladas, assim, na véspera. Foram canceladas porque deu um problema no gerador de energia e tal, e nós avisamos as pessoas pelo Twitter, os alunos. Não só pelo Twitter, usamos também site, usamos imprensa, divulgação externa, mas também o Twitter. E foi ali que "bombou" o nosso número de seguidores. Ali a gente viu, também, o poder das mídias sociais, porque muita gente "retuitava", divulgava pros colegas e tal, e nós começamos a... vamos dizer assim... focar mais nas mídias sociais. Aí que se começou a pensar no que a gente poderia fazer com essas mídias. ${ }^{6}$

Conforme defendem os autores Qualman (2009) e Saad Corrêa (2009), um dos principais diferenciais do uso das mídias sociais em relação às mídias tradicionais - televisão, rádio, jornais etc. - é que as pessoas integrantes da mesma rede social podem, dependendo do teor da mensagem propagada, tornarem-se parceiros da organização, replicando a mensagem produzida pela instituição quando esta é considerada relevante. $\mathrm{O}$ episódio do cancelamento de aulas, citado acima, evidencia o potencial de alcance das ações de divulgação utilizando mídias sociais.

A incorporação dos serviços de mídia social junto aos canais de comunicação tornou possível o estabelecimento de comunicação do tipo "mão dupla" entre o Instituto Federal e seus públicos. De acordo com os entrevistados, os canais de comunicação mais consolidados na instituição e que estabelecem o contato entre a organização e os seus públicos - como, por exemplo, o Jornal Contato, o Link Digital, a intranet e o site externo - não apresentam possibilidade de interação.

A gente está muito acostumada aqui dentro - e quando digo eu "a gente", é o próprio Instituto em si - a fazer, produzir as ferramentas, divulgar e deu. Tá preocupado em informar, divulgar e informar, mas não a ouvir o retorno. Então, hoje, quando a gente divulga alguma coisa, em alguma mídia social, que permite que as pessoas comentem, dê retorno, a gente tá ali, dando a cara à tapa. A gente divulga uma coisa, a pessoa "ah, mas aqui não acontece assim", "ah, mas por que aqui não tem?", sabe? [...] Então, o que acontece: acaba dando um pouco mais de credibilidade pra instituição também, e transparência. ${ }^{7}$

\footnotetext{
${ }^{6}$ Transcrição de entrevista realizada com coordenador de Jornalismo.

${ }^{7}$ Transcrição de entrevista realizada com coordenador de Jornalismo.
} 
De acordo com Bateman e Snell (2006), a comunicação de mão única é muito mais frequente nas organizações do que deveria ser, pois é mais rápida e fácil para o emissor. A mão dupla, porém, é mais precisa, gerando menos problemas e mais satisfação das partes envolvidas. Entre os principais benefícios apontados pelos autores estão: oportunidade para os receptores fazerem perguntas e compartilharem preocupações; maiores chances de os receptores promoverem sugestões ou modificações; maior entendimento da mensagem que é comunicada e do que deve ser feito com a informação.

As impressões de modernidade, transparência e a credibilidade passadas ao público por meio de ações realizadas nas mídias sociais são fatores recorrentes, destacados pelos profissionais entrevistados. Segundo eles, graças às mídias sociais o público passou a ter mais informações e a se aproximar mais da instituição.

Com certeza, hoje, quem nos segue nas redes sociais tem essa impressão de instituição, ali, de transparência, de uma instituição que está aberta a ouvir, a abrir canais de diálogo com o público, com credibilidade ${ }^{8}$

Até teve aluno que colocou lá no Twitter pessoal: "A sua escola tem Twitter? Ah, não tem? A minha tem" e tal, dando a ideia, assim, de que é algo... "ó, a minha escola tem, é moderna", coisa assim. E principalmente pra uma instituição pública, que é vista como aquela coisa, assim, muito burocrática, até às vezes atrasada. Acho que os canais de mídias sociais têm esse papel de mostrar que a instituição está ligada nas novas ferramentas de comunicação. ${ }^{9}$

Essas impressões vão ao encontro da necessidade apontada por Saad Corrêa (2009) de que as instituições públicas deixem, aos poucos, de atuar apenas num modelo estagnado de produção de informações. Para a autora, essas instituições devem atuar como agentes sociais de referência em suas redes e como produtoras de informações "em fluxo", de forma social e interativa.

Por fim, a comunicação de mão dupla passou a dar um caráter de ouvidoria ao setor de comunicação da instituição. Essa transformação é tida como positiva pelo setor de comunicação, uma vez que poucas chances eram dadas aos alunos e à comunidade para interagirem institucionalmente com o IF-SC.

É engraçado porque os alunos são as grandes estrelas dessa instituição. Só estamos aqui porque tem alunos, e a gente não tinha, assim, mecanismos talvez adequados pra contato com aluno. A criação do jornal impresso foi

\footnotetext{
${ }^{8}$ Transcrição de entrevista realizada com coordenador de Jornalismo.

${ }^{9}$ Transcrição de entrevista realizada com coordenador de Jornalismo.
} 
uma iniciativa de ter um contato maior com os alunos que não tinham acesso à intranet e não tinham acesso a e-mail da instituição. Só que, ainda assim, tem alunos, principalmente os mais jovens, na faixa de 15 a 18 anos, que acham o jornal impresso meio "quadradão", meio institucional, e querem algo diferente. Então acho que as redes sociais vieram pra aumentar esse contato com eles. ${ }^{10}$

Uma das respostas a essa questão tem sido o respaldo alcançado pelas mídias sociais do IF-SC junto a uma parcela significativa dos alunos e da comunidade. Além de ter alcançado centenas de conexões em sua página no Facebook, o IF-SC também figura com destaque quanto à utilização do Twitter em meio às instituições que compõem a Rede Federal de Educação Profissional e Tecnológica. O perfil do IF-SC no Twitter, em 2010, foi o terceiro com mais seguidores dentre os Institutos Federais, alcançando 2458 seguidores em dezembro (IF-SC, 2011).

Ainda que a Diretoria de Comunicação não trabalhe com metas estabelecidas para as ações ou para os canais de mídia social, os resultados alcançados até o momento têm sido em sua maioria positivos, o que surpreende a equipe.

Entretanto, identificou-se um caso que não atendeu às expectativas da Diretoria. Ele ocorreu no Twitter, quando os profissionais pensaram que os seguidores do perfil “@ifsc” os ajudariam a disseminar uma campanha sobre a mudança na forma de ingresso nos cursos superiores da instituição.

Eu lembro, quando o IF-SC passou a adotar exclusivamente o Enem, que a gente quis criar no Twitter uma hashtag \#IFSC100\%ENEM, e a gente achou que ia ter uma repercussão maior, até pra ajudar na divulgação. [...] E aquilo foi um negócio que, pelo menos pessoalmente, eu achava que ia ter mais repercussão, enquanto outros casos como aquele anterior que eu citei [adiamento das aulas do campus Florianópolis] teve bem mais do que a gente imaginava. ${ }^{11}$

No entanto, a maioria dos resultados tem agradado aos integrantes da Diretoria de Comunicação, inclusive surpreendendo aqueles que lidam diretamente com as mídias sociais, como o coordenador de Jornalismo:

Não vou dizer que esperava pouco, mas talvez, lá em dezembro de 2008, eu não achasse que o Twitter ia ser tão importante assim pra comunicação da instituição, que fosse ter esse impacto tão grande com alunos e comunidade. [...] No geral, nesses dois anos de uso, foi assim... Quer dizer, um pouco eu

\footnotetext{
${ }^{10}$ Transcrição de entrevista realizada com coordenador de Jornalismo.

11 Transcrição de entrevista realizada com jornalista.
} 
já esperava, não vou dizer assim que a gente não esperava que tivesse sucesso, mas foi... Está sendo, talvez, uma experiência muito interessante. ${ }^{12}$

Os benefícios, resultados e desafios percebidos pelos profissionais do IF-SC a respeito da utilização das mídias sociais são, porém, fruto de um processo de inovação. E, tal como outro processo de inovação, a adaptação à realidade da instituição de ensino foi um processo dinâmico, no qual os responsáveis pelas mídias sociais observaram o comportamento dos alunos frente a esse novo canal de comunicação.

No Facebook, por exemplo, a gente começou a perceber que estava crescendo. Criamos, em princípio, um grupo, que não deu muito certo, pois funcionava mais como um grupo de discussão. Depois, esse grupo nós abortamos e aí criamos uma página, que foi também ideia de um dos nossos jornalistas, com base numa participação dele em um evento dessa área em São Paulo. Aí criamos a página e aí deu certo. [...] Com base até na experiência que a equipe começou a ter com participação em eventos, que envolviam mídias sociais, contatos com outras instituições, começamos a criar essas novas ferramentas, como o nosso Orkut, o perfil no Formspring... ${ }^{13}$

A iniciativa e a percepção do setor coadunam com o que é sugerido por Weinberg (2009) quanto à presença de instituições em mais de uma mídia social. Para a autora, essas instituições devem se fazer presentes e ativas nas mídias sociais em que seu público-alvo está.

Percebe-se ainda, que, ao mesmo tempo em que os incentivos internos à utilização e à disseminação das mídias sociais sejam informais, existe uma recomendação formal do próprio Ministério da Educação para que ocorra esse estímulo, principalmente para favorecer a comunicação junto a alunos, comunidade e imprensa. Esse descompasso parece ter sido percebido pelo IF-SC e, sobre esse assunto, foi estruturada a próxima categoria de análise.

\subsection{Dificuldades que se tornam desafios}

Em virtude de o Instituto Federal ser uma instituição com características específicas, o setor de comunicação necessita da colaboração dos coordenadores de Extensão e Relações Externas de cada campus. Esses profissionais, porém, não possuem, necessariamente, formação ou experiência na área de comunicação. Mesmo assim, eles têm entre suas responsabilidades a de alimentar os canais de comunicação utilizados pelo campus, o que

\footnotetext{
12 Transcrição de entrevista realizada com coordenador de Jornalismo.

${ }^{13}$ Transcrição de entrevista realizada com coordenador de Jornalismo.
} 
inclui as mídias sociais. Surge, então, a dificuldade de coordenação e de comunicação entre os próprios profissionais ligados a essa atividade dentro da instituição.

Com vistas a minimizar os efeitos negativos que esse desafio impõe à própria área, a Diretoria de Comunicação realizou, em 2010, encontros entre seus integrantes e os coordenadores de Extensão e Relações Externas. Esses encontros tiveram um caráter de capacitação e estavam entre as ações planejadas da Diretoria de Comunicação para aquele ano (IF-SC, 2010b).

Além da coordenação das ações, o monitoramento dos resultados obtidos também mereceu atenção como um dos desafios para o uso das mídias sociais. Conforme percebido nas entrevistas, esses resultados ainda são obtidos por meio de indicadores adotados empiricamente pelos profissionais que lidam com as mídias sociais.

É empírico mesmo. As ferramentas de monitoramento existem, mas não existe um processo, como toda semana fazer um relatório pra ver como é que anda a força dessas mídias sociais na comunicação do IF-SC. O que a gente faz hoje, muito mais por curiosidade, é pra saber se a gente está crescendo, até pra justificar o trabalho, mais do que realmente um procedimento padrão. ${ }^{14}$

Segundo Weinberg (2009), o trabalho envolvendo mídias sociais precisa ser acompanhado e monitorado ao longo do tempo. Esse tempo, por sua vez, pode aproximar-se mais do longo prazo do que do curto prazo, até que sejam percebidos resultados ou mudanças deflagradas devido aos esforços empregados nos canais de mídia social. A autora indica a necessidade de que seja realizado um acompanhamento regular das ações e repercussões ocorridas nos canais de mídia social, não somente para justificar o trabalho desenvolvido, mas, também, para que sejam percebidas tendências, oportunidades ou outros indícios relevantes ao trabalho desempenhado pela instituição.

Outra dificuldade enfrentada é a pouca disponibilidade de pessoal para lidar com as ferramentas de comunicação existentes ou que possam ser adotadas. Segundo os entrevistados, há a preocupação em manter a qualidade das ferramentas já utilizadas, o que impede que novas ideias sejam postas em prática sem que se abra mão de alguma ferramenta atual.

\footnotetext{
${ }^{14}$ Transcrição de entrevista realizada com jornalista.
} 
Cabe destacar que a disponibilidade limitada de tempo por parte dos profissionais que lidam com a comunicação afeta não somente a adoção de novos canais de mídia social, mas a adoção das mídias sociais propriamente ditas em detrimento de outras atividades realizadas.

Nesse contexto, algumas das maiores barreiras enfrentadas para a implantação de uma cultura que aproveite os benefícios e as possibilidades oferecidas pelas mídias sociais parecem estar relacionadas aos próprios servidores da instituição, inclusive os gestores. De acordo com as entrevistas, os profissionais da área de comunicação têm dificuldade para avançar ou disseminar o uso desse tipo de mídia junto aos próprios servidores. Por outro lado, junto aos demais públicos-alvo (alunos, imprensa e comunidade externa), percebe-se uma afinidade quanto à utilização de mídias sociais.

Entre as razões encontradas para explicar esse fenômeno está o desconhecimento por parte dos servidores acerca dos benefícios ou das possibilidades de aplicação dessas ferramentas. Também é apontada a existência de preconceito em relação a esses canais de comunicação.

Quem dirige a instituição, os "dirigentes máximos", digamos, os diretoresgerais, os pró-reitores, eles são de uma geração que não conhecia mídias sociais. Então eu diria, ainda, que o grande empecilho que nós temos pra efetiva implantação [das mídias sociais no IF-SC] é o desconhecimento por parte deles. ${ }^{15}$

[...] não só pela questão da idade, mas muitos servidores não têm essa cultura de participar das redes sociais. Então, a dificuldade é fazer as pessoas compreenderem o que é essa mídia social, qual que é o objetivo, para que serve. E, também, como as pessoas não conhecem, às vezes acabam tendo medo de usar ou colocar a própria instituição nesse universo. ${ }^{16}$

Para diminuir essa resistência, a Diretoria de Comunicação organizou um encontro com servidores da área de comunicação dos campi, a quem foram apresentadas as ferramentas de mídia social e os benefícios que elas podem proporcionar. No entanto, a limitação de tempo para o encontro (cerca de duas horas para os servidores e de 20 minutos para os gestores) evidenciou uma barreira relativa à disseminação de uma cultura que tire proveito da existência das diferentes ferramentas de comunicação.

Percebe-se que, embora tenham sido obtidos resultados positivos na área de comunicação utilizando-se as mídias sociais, ações envolvendo esse tipo de mídia ainda são

\footnotetext{
${ }^{15}$ Transcrição de entrevista realizada com diretor de Comunicação.

${ }^{16}$ Transcrição de entrevista realizada com coordenador de Jornalismo.
} 
limitadas. As análises apresentadas mostram que muitos passos foram dados, mas muito espaço ainda há para ser conquistado, tanto pela área de comunicação quanto pelas mídias sociais propriamente ditas. Percebe-se ainda que existe uma disposição em buscar essa expansão, como afirma o diretor de Comunicação: "Mas eu aposto 100\% em mídias sociais como ferramenta de modernidade, como ferramenta eficaz, eficiente. Não tem mais como virar a cara e dizer 'ah, isso não dá certo'. Isso já deu certo"17.

\section{CONCLUSÕES}

A comunicação com o público-alvo é fator relevante para que uma instituição de ensino cumpra se papel social. No IF-SC, a Diretoria de Comunicação possui a função de gerir os meios de contato dos diferentes públicos-alvo.

Frente à atuação do IF-SC na sociedade e às mudanças tecnológicas que permeiam os dias atuais, as mídias sociais surgem como mais uma possibilidade de comunicação institucional com a sociedade, numa perspectiva inovadora, cujo objetivo principal é melhorar o fluxo de informações relevantes e diminuir a distância existente junto a alunos, servidores e a comunidade externa. Assim, o IF-SC utiliza as mídias desde 2008, no sentido de estabelecer uma relação direta com representantes dos três públicos citados.

É consenso entre os entrevistados que muitas dificuldades apontadas estão ligadas a limitações internas e externas, inclusive aos valores e crenças de parte da equipe gestora da instituição. Trabalhar de forma a disseminar a cultura de inovação e apoio às mídias sociais envolve, necessariamente, conscientizar o grupo gestor do IF-SC como um todo.

$\mathrm{O}$ aumento do acesso à informação, a influência sobre a credibilidade das mensagens comunicadas e o poder multiplicador exercido pelos usuários das mídias sociais estão entre os principais atrativos para que as instituições de ensino insiram suas mensagens nesses ambientes. Além disso, as possibilidades de comunicação abertas pelo mundo digital são muitas e seu poder comunicativo não está, necessariamente, relacionado à capacidade financeira da organização que se comunica.

No IF-SC, nota-se que as mídias sociais têm promovido resultados positivos para a instituição, ainda que haja conflitos e barreiras que precisam ser trabalhadas. Dentre elas destacam-se: aproximação da instituição de ensino junto aos alunos e à comunidade; estabelecimento de canais efetivos de comunicação, com a possibilidade de troca (mão dupla)

\footnotetext{
${ }^{17}$ Transcrição de entrevista realizada com diretor de Comunicação.
} 
entre instituição e público; aumento da importância da área de comunicação, que passou a receber diversas demandas por informação e começou a atuar de forma mais sistêmica; facilitação do acesso às informações sobre a instituição de ensino; maior credibilidade e transparência, fatores especialmente relevantes em instituições públicas.

Em meio a esse contexto, também foram identificadas dificuldades ou desafios. Dentre eles, se destacam os seguintes: desconhecimento acerca dos benefícios ou possibilidades de aplicação das mídias sociais por parte, principalmente, dos servidores e gestores da instituição; baixo incentivo formal para adoção das mídias sociais como canal oficial de comunicação institucional; pouca disponibilidade de pessoal para lidar com as possíveis ferramentas de comunicação, inclusive as mídias sociais; falta de preparo de parte dos servidores responsáveis para auxiliar na manutenção de canais de comunicação do IF-SC, entre eles as mídias sociais.

A adoção de mídias sociais, por uma instituição pública de ensino, para se comunicar com alunos, servidores e comunidade externa é, porém, uma evidência de que, também na área da educação, as organizações podem e devem adaptar-se às mudanças e demandas de cada época. Com a expansão do acesso à internet, novas formas de pensar, de agir, de se comunicar, de produzir conhecimento emergem no ciberespaço, possibilitando mudanças. Nesse sentido, as mídias sociais se configuram como canais cada vez mais significativos para a comunicação das pessoas e das instituições.

\section{REFERÊNCIAS}

BARDIN, Laurence. Análise de conteúdo. Lisboa: Edições 70, 2009.

BATEMAN, Thomas S.; SNELL, Scott A. Administração: novo cenário competitivo. 2. ed. São Paulo: Atlas, 2006.

BRASIL. Lei no 9.394, de 20 de dezembro de 1996. Estabelece as diretrizes e bases da educação nacional. Diário Oficial da União, Brasília, DF, 24 dez. 1996. Disponível em $<$ http://portal.mec.gov.br/seed/arquivos/pdf/tvescola/leis/lein9394.pdf $>$. Acesso em: 30 jun. 2010.

Lei $n^{\circ} 11.892$, de 29 de dezembro de 2008. Institui a Rede Federal de Educação Profissional, Científica e Tecnológica, cria os Institutos Federais de Educação, Ciência e Tecnologia, e dá outras providências. Diário Oficial da União, Brasília, DF, 30 dez. 2008b. Disponível em <http://www.planalto.gov.br/ccivil_03/_ato2007-2010/2008/Lei/L11892.htm>. Acesso em: 10 dez. 2010. 
DELORS, Jacques (Coord.). Educação, um tesouro a descobrir: relatório para a Unesco da comissão internacional sobre educação para o século XXI. São Paulo: Cortez Editora, 1998. Disponível em: $<$ http://www.dominiopublico.gov.br/download/texto/ue000009.pdf $>$. Acesso em: 29 jul. 2010.

HAY, Deltina. A survival guide to social media and web 2.0 optimization: strategies, tactics, and tools for succeeding in the social web. Austin: Dalton Publishing, 2009.

IF-SC, Instituto Federal de Educação, Ciência e Tecnologia de Santa Catarina. Plano de Desenvolvimento Institucional. Florianópolis, 2009. Disponível em:

$<$ http://intranet.ifsc.edu.br/images/file/Publicacoes/PDI\%20para\%20MEC\%20

29\%20de \%20junho\%202009\%20COM\%20ead.pdf>. Acesso em: 12 dez. 2010. Acesso restrito.

Caderno de Indicadores. Florianópolis, 2010a. Disponível em: <

http://www.ifsc.edu.br/>. Acesso em: 31 ago. 2010.

Planejamento 2010. Florianópolis, 2010b. Disponível em:

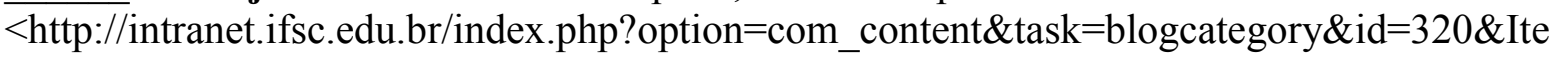
mid=496>. Acesso em: 8 out. 2010. Acesso restrito.

Computador da Coordenadoria de Jornalismo. Jornalismo_Relatório_2010.docx. Florianópolis, 2011. 1 arquivo (3.942.404 bytes).

INSTITUTO NACIONAL DE ESTUDOS E PESQUISAS EDUCACIONAIS ANÍSIO TEIXEIRA (INEP) (Brasil). Ministério da Educação. Inep. Disponível em:

$<$ http://www.inep.gov.br>. Acesso em: 13 jan. 2011.

KAPLAN, Burton. Comunicação estratégica: a arte de transmitir idéias. Rio de Janeiro: LTC, 1993. $221 \mathrm{p}$.

LAS CASAS, Alexandre L.; LAS CASAS, Jéssica L.. A situação atual dos ensinos básico, médio e superior. In: LAS CASAS, Alexandre L.. Marketing educacional: da educação infantil ao ensino superior no contexto brasileiro. São Paulo: Saint Paul Editora, 2008.

OLIVEIRA NETTO, Alvim A. de. Metodologia da pesquisa científica: guia prático para apresentação de trabalhos acadêmicos. 3. ed. rev. e atual. Florianópolis: Visual Books, 2008.

QUALMAN, Erik. Socialnomics: how social media transforms the way we live and do business. Hoboken: Wiley, 2009.

SAAD CORREAA, Elizabeth. Comunicação de governo na era das mídias sociais. Brasília, 2009. Palestra realizada no Anexo I do Palácio do Planalto em 14 de jul. de 2009.

SAFKO, Lon; BRAKE, David K. The social media bible: tatics, tools \& strategies for business sucess. Hoboken: Wiley, 2009.

STEINER, Philippe. A sociologia econômica. São Paulo: Atlas, 2006. 
VALLE, James D. Facebook é o primeiro nos Estados Unidos. Info Online, São Paulo, 30 dez. 2009. Disponível em: <http://info.abril.com.br/noticias/internet/facebook-e-o-primeironos-estados-unidos-30122009-3.shl>. Acesso em: 20 ago. 2010.

WEINBERG, T. The new community rules: marketing on the social web. 1. ed. Sebastopol: O'Reilly Media, 2009.

YIN, R. K. Estudo de caso: planejamento e métodos. 3. ed. Porto Alegre: Bookman, 2005. 